\title{
A FUNÇÃO DA RELIGIÃO NA CONSTRUÇÃO SOCIAL DA MASCULINIDADE
}

\author{
The Role of Religion in Social Construction of Masculinity \\ El Rol de la Religión en la Construcción Social de la Masculinidad
}

CLÓvis ECCO

\begin{abstract}
Resumo: Este artigo versa sobre a função da religião na construção social da masculinidade. Visa compreender a influência das idéias religiosas na construção social da identidade masculina. Para atingir este objetivo, procura-se compreender a influência da religião na construção social da masculinidade e, também, compreender os motivos sociais e religiosos que propiciam a instituição da supremacia hierárquica masculina.
\end{abstract}

Palavras-chave: Gênero; Religião; Masculinidade; Identidade.

Abstract: This article is about the role of religion in the social construction of masculinity. The main objective is to understand the influence of religious ideas in the social construction of male identity. To achieve this goal, seeks to understand the influence of religion in the social construction of masculinity and also understand the social and religious reasons that provide the institution of hierarchical male supremacy.

Keywords: Gender; Religion; Masculinity; Identity.

Resumen: Este artículo versa sobre el rol de la religión en la construcción social de la masculinidad. Visa comprender la influencia de las ideas religiosas en la construcción social de la identidad masculina. Para lograr este objetivo, trata de comprender la influencia de la religión en la construcción social de la masculinidad y también entender los motivos sociales y los motivos religiosos que favorecen la institución jerárquica de la supremacía masculina.

Palabras-clave: Género; Religión; Masculinidad; Identidad.

\section{A Importância da Religião na Formação Social da Identidade de Gênero}

Creio não ser necessário discutir a importância das idéias religiosas na formação da masculinidade na estrutura social e cultural do Ocidente. Somente a título de exemplo, gostaria de mencionar que, em pesquisa $^{1}$ realizada em 2006, para o Mestrado em Ciências da Religião pela Universidade Católica de Goiás, na Região Leste de Goiânia, mesmo o tema não sendo a construção social da masculinidade - entre 49 pessoas do sexo masculino, 46 deles apontaram a doutrina da religião católica como estruturadora e mantenedora da supremacia da identidade masculina. Afirmava-se que a imagem consagrada e alicerçada em nossa tradição é de uma figura masculina de Deus, e por isso, segundo os entrevistados, assumiam-se mais próximos e preferidos. No entanto, ser homem em tão grande estima, dão a eles a prerrogativa da supremacia na relação com o universo feminino.

Um exemplo da supremacia da masculinidade é quando nas relações cotidianas apresentarem problemas, logo

\footnotetext{
A pesquisa foi realizada na região Leste de Goiânia, tendo sido aprovada no CEP em 04 de maio de 2006, com o Código 86854.
}

é evidenciado pela pesquisa que o masculino tem a legitimidade moral de respaldar o conflito, devido à maior identificação com a divindade, já que Deus é homem.

Os entrevistados foram pessoas do sexo masculino que estavam vinculadas à Igreja Católica, devido ao fato de terem recebidos toda a formação básica da doutrina canônica da Instituição, onde o homem exerce a supremacia na condução ministerial e doutrinal. Foi observada também a faixa etária acima de trinta anos de idade, solteiro ou casado, cuja idade lhe proporciona uma leitura sobre a compreensão de si e da masculinidade.

No seio de nossa cultura, as idéias religiosas permanecem com grande peso, e em todas as expressões religiosas oriundas da tradição cristã há muita ênfase na manutenção da supremacia masculina. Tais considerações levaram-nos a elaborar a pergunta que norteará toda a pesquisa, que é: como se gesta e se mantém a supremacia social na construção da identidade de gênero masculino e qual é a sua característica predominante?

Para atingir este objetivo, procuraremos compreender quais são os valores sociais e religiosos que propiciam a instituição da supremacia hierárquica masculina, a partir da concepção cultural e da tradição que Deus é um ser masculino, uma vez que falar de masculinidade pressupõe falar de objetividade, responsabilidade, tradição, potência, 
providência, virilidade, palavras que significam poder na inter-relação social de gênero.

Com toda certeza, sabemos que a problemática levantada não será esgotada neste artigo, mas, tentar-se-á lançála com intuito de que propicie uma maior reflexão e produção do conhecimento para além deste artigo.

Parte-se da perspectiva de que mais instituições sociais contribuem para a construção social do masculino em nossa realidade. Quando nós nascemos, o Estado é responsável por assegurar os direitos de cada indivíduo e dos sujeitos sociais, claro, desde que o indivíduo cumpra com a sua função, que é o desempenho social esperado. Da mesma forma, a família, que é uma instituição profundamente importante para a manutenção do poder; e a Escola, que é uma das primeiras instituições que tem a responsabilidade de socialização, e o compromisso da assimilação dos direitos e deveres do cidadão, simultaneamente com a orientação. Logo, são inúmeras - a partir dos exemplos dados acima - as instituições responsáveis pela construção social dos sujeitos, todas com características diferentes, porém com o mesmo objetivo: integrar e socializar ao meio social em que as pessoas vivem. A nossa intenção é observar como se dá esta construção social da supremacia da masculinidade na realidade social, a ponto de uma sociedade ser constituída de indivíduos com características físicas, psicológicas e espirituais particulares, porém, com ações sociais "esperadas", o que chamaria Bourdieu de "habitus".

Entende-se que enquanto a realidade para o sujeito religioso desempenha papel ativo na elaboração e na manutenção desses habitus, ela existe, é verdadeira, é experiencial, e, algumas vezes, é "o tudo da vida do indivíduo" (Geertz, 1989), pois é seu referencial primeiro de significado. Apresenta-se como experiência permanente e profunda das mais diversas formas de manifestações do sagrado. Paden (2001, p. 117), afirma que "os deuses estão vivos, afinal - dentro da psique”. Afirmação essa que contraria as afirmações de Freud que considerava a religião como "pura ilusão" e apóia a teoria de Jung, que considera a experiência religiosa como "uma ilusão muito real”. Não compreendemos a religião como algo ilusório, desprezível; consideramos a religião uma esfera importante e marcante na construção social do indivíduo. Concordamos com Geertz (1989, p. 103) ao afirmar que:

(...) os símbolos sagrados funcionam, para sintetizar o ethos de um povo - o tom, o caráter e a qualidade da sua vida, seu estilo e disposições morais e estéticos - e sua visão de mundo - o quadro que fazem do que são as coisas na sua simples atualidade, suas idéias mais abrangentes sobre a ordem.

\footnotetext{
Sistema de disposições inconscientes que constituem o produto da interiorização das estruturas objetivas e que, enquanto lugar geométrico dos determinismos objetivos e de uma determinação, do futuro objetivo e das esperanças subjetivas, tende a produzir práticas e, por esta via, carreiras objetivamente ajustadas às estruturas objetivas (Bourdieu, 1998, pp. 201-202).
}

Ainda, segundo Geertz, os símbolos sagrados têm a capacidade de estabelecer padrões morais, sociais e estéticos, que são assumidos pelo indivíduo enquanto realidade. Este estabelecimento dá a idéia de realidade eterna para o grupo, a tal ponto que essas realidades depois de objetivadas, passam a fazer parte da cosmovisão dos sujeitos sociais. Esse processo é estabelecido na dinâmica do tempo e na capacidade que a religião tem em estabelecer "suas realidades" sobre o corpo dos sujeitos religiosos Ele se dá desde a "chegada ao mundo". É o que consideramos como processo de socialização. De acordo com Geertz (1989, p. 136):

A religião é sociologicamente interessante não porque, como o positivismo vulgar o colocaria, ela descreve a ordem social (e se o faz é de forma não só muito oblíqua, mas também muito incompleta), mas porque ela - a religião - a modela, tal como o fazem o ambiente, o poder político, a riqueza, a obrigação jurídica, a afeição pessoal e um sentido de beleza.

Na afirmação do referido autor, a religião tem a capacidade, assim como o meio ambiente, de "modelar" os sujeitos, tamanha sua influência social. Por isso, consideramos o campo simbólico, desde os mecanismos mais sutis de influência religiosa na vida dos sujeitos, como um espaço privilegiado para entender a construção social da supremacia cultural da masculinidade. Entendemos que a constituição da subjetividade se dá por meios - como diria Geertz - "modelatórios", ou seja, sob a influência de uma gama de formas de religiosidade.

Fuller (2001) já apresenta o processo de construção da identidade nos diferentes momentos da vida e, que não termina com as primeiras assimilações da infância. É um processo que prossegue durante toda a vida. Cada vez que a pessoa ingressa num novo cenário institucional, incorpora um novo processo de socialização secundária. Para Bourdieu (2005, p. 118), o mundo social funciona como um mercado de "bens simbólicos" dominado pela visão masculina. "Ser, quando se trata de mulheres, é ser percebido pelo olhar masculino, ou por um olhar marcado pelas categorias masculinas". Segue o autor afirmando que quando se elogia uma obra de mulher por "ser feminina", é essencialmente uma forma de evitar todas as propriedades e práticas que podem funcionar como sinais de virilidade. "Dizer de uma mulher de poder que ela é 'muito feminina' não é mais que um modo particularmente sutil de negar-lhe qualquer direito a este atributo caracteristicamente masculino que é o poder".

Nesse sentido, afirma também Fuller (2001) que, a diferença anatômica entre o corpo masculino e o corpo feminino tem servido como justificativa natural para a diferença social entre os gêneros. Na análise dessa perspectiva da cultura patriarcal, na qual vem se desenvolvendo, se percebe que "toda versão da masculinidade que não corresponda à dominação seria equivalente a uma maneira precária de ser masculino, que pode ser submetido ao 
domínio por aqueles que ostentam a qualidade plena de homem" (Fuller, 2001, p. 24).

Apesar de ser uma característica cultural-patriarcal de identidade de gênero, há uma definição, a priori, das características da masculinidade. Afirma ainda a autora que "os homens não têm opção de escolher suas preferências sexuais ou os papéis que cabe desempenhar ao longo de suas vidas" (Fuller, 2001, p. 25). O masculino assumirá uma identidade de gênero instituída culturalmente, que supõe ocupar posições sociais determinadas, isto é, ter filhos legítimos, ser heterossexual, ser provedor da casa. "Quem não assume estes mandatos cairá num vazio social". Ou seja, carecerá de uma identidade de gênero reconhecida ou formará parte da galeria da masculinidade marginalizada e sofrerá as sanções sociais correspondentes (Fuller, 2001, p. 25).

Ainda na perspectiva de ocupar posições sociais determinadas, quem não assume "cairá no vazio" para Fuller (2001). Confirma-se esta compreensão da postura masculina, no fato ocorrido na madrugada do dia 04 de julho de 2008, quando um sargento do Exército foi detido pela Polícia da mesma Instituição, após ser entrevistado por um programa de TV, em São Paulo e, foi preso ao sair dos estúdios da emissora. O motivo da prisão foi que o Militar reafirmou a sua homossexualidade em entrevista. No flagrante, alegou-se que o crime foi praticado pela "deserção", não por ele ter negado a sua heterossexualidade. $\mathrm{Ou}$ seja, o Militar estava pondo em dúvida "a identidade de gênero reconhecida pela sociedade como ocupar posições legitimas e determinadas" (Fuller, 2001, p. 25).

Seguindo a mesma perspectiva, percebe-se que há uma cultura social da masculinidade com características próprias na construção da relação social da identidade de gênero com aspectos bem globais. Compreende-se pela própria identidade histórico-cultural, que o homem seja bem relacionado em sua vida social e estabilizado financeiramente. Compreende-se ainda que os homens sejam poderosos, racionais, viris, não emotivos e agressivos (quando necessário). Para Fuller (2001) é preciso mostrar que a própria masculinidade é refém dessas exigências históricas e culturais. E quem não consegue representar a masculinidade nos parâmetros esperados, cai no ostracismo e passa a ser considerado o outro, o excluído, ou então se usa o pretexto para se afirmar que o crime foi praticado pela "deserção".

\section{As Concepções da Divindade}

A masculinidade, compreendida nesta circunstância, segundo Cechetto (2004), estaria em crise:

A crise da masculinidade tem suas origens nas transformações globais econômicas e geopolíticas que se abateram sobre os EUA, desde o início do século XX. Tais reestruturações promoveram uma reformulação nas definições tradicionais da masculinidade (pp. 61-62).
A construção da representação masculina trouxe um conflito que gerou a crise da masculinidade, ou seja, a crise consistia no confronto direto entre o que se esperava que o homem fosse, e o que de fato ele era. No caso da sociedade brasileira, em um determinado momento, os homens começaram a perder seu campo de trabalho, por falta de especialização, quando o mercado buscava mão de obra especializada. Homens que até então eram considerados ativos, com quarenta anos não "servem mais" para o mercado global. E como viver em uma sociedade em que o homem não consegue se representar enquanto "homem"?

A necessidade de respostas às questões postas pela crise de masculinidade nos leva a centrar nossa atenção na análise sobre a forma como a instituição da religião, assim como a instituição da família, contribuíram para significar e justificar as representações masculinas e a construção do "tornar-se homem".

Entendemos que a religião seria uma parceira da instituição familiar e social na ação de legitimar a supremacia da masculinidade, e ao mesmo tempo, daria legitimidade por meio do discurso religioso. Segundo Geertz, as construções religiosas são "penetrantes e duradouras". Histórias míticas do tipo "Deus formou o homem do pó da terra e tirou de sua costela a mulher". Ou, como essa leitura de São Paulo aos Efésios (5,23-25) que ouvíamos no domingo, dia 31 de agosto de 2006: "mulheres sejam submissas aos seus maridos como o senhor. Pois o marido é a cabeça da mulher, do mesmo modo que Cristo é a cabeça da Igreja", dão à representação masculina a primazia sobre todas as coisas, principalmente sobre a mulher, criada em segundo lugar.

No intuito de verificar como essa concepção de masculinidade faz-se presente no cotidiano das relações sociais, apresentamos alguns dados da pesquisa de campo realizada em 2006, para o Mestrado em Ciências da Religião pela Universidade Católica de Goiás, na Região Leste de Goiânia.

Foi elaborado um questionário de apoio para o entrevistador com oito questões sobre o tema em foco. Uma das perguntas se referia sobre o que é ser um homem (pessoas do sexo masculino)? Mais de 90\% dos entrevistados afirmaram que o homem é o chefe e a cabeça da família.

"o homem é o chefe e a cabeça da família, por isso, na casa ele deve ser respeitado” (M.S.L., 48 anos).

"O homem é o chefe da família e precisa ter responsabilidade de trabalhar de educar e de conduzir a família” (B.R.M., 42 anos).

"O homem foi colocado por Deus no mundo para "gerenciar a família, para juntar-se com uma mulher e formar uma família. É o homem que vai ser a pessoa responsável por ela (mulher) e criar os filhos”. (C.C, 51 anos)

Na mesma perspectiva, afirma outro entrevistado que: 
"para ser pessoa do sexo masculino é obrigação exercer uma liderança. Às vezes até sobre as mulheres, mas em prol delas, as elevando, jamais as diminuindo. Então ser homem é assumir obrigações, além das obrigações femininas, seja no sentido de prover o lar ou no sentido material, assistencial e, sobretudo, espiritual. Então o homem por apalpar sua vida pela razão em relação à mulher, ele deve servir para o bem".

Podemos entender essas afirmações à luz do mito cristão da queda humana, que afirma que logo após a queda do homem, no momento em que fora lançado fora do paraíso, Deus determina que o homem trabalhe para sustentar a instituição familiar, enquanto que a mulher servirá para gerar vida. Apesar de a contemporaneidade ser portadora de novos mitos, como o da supremacia da ciência, essas idéias religiosas não perderam sua influência cultural no processo de sacralização das representações sociais sobre a masculinidade.

Não podemos ignorar o fato de que a literatura de nossa língua está intimamente ligada com a história particular de um Deus masculino (monoteísmo).

Essa concepção de que a divindade é masculina se faz presente nas falas das seguintes pessoas entrevistadas, quando perguntados se na compreensão deles Deus é masculino ou feminino.

"Para mim Deus é homem porque foi criado pelo pai. Foi enviado para a terra para salvar a todos nós. Por isso, eu acho que Deus é homem” (L.S.A., 67 anos).

"Deus! Pelo que é tratado eu não sei se é pelo fato da sociedade ser machista dá-nos a impressão que ele é homem" (L.J.B, 30 anos).

"Na minha opinião, Deus é masculino. Porque eu acho que ele é todo poderoso e manda em tudo, por isso, eu acho que ele é homem" (A.R.F., 60 anos).

Podemos entender essas afirmações a partir da reflexão de Croatto (2001), quando afirma que a linguagem que fazemos das coisas sempre é simbólica e representativa. $\mathrm{Na}$ comunicação com o transcendente, temos compreensões de Deus a partir de analogias que fazemos de pessoas. $\mathrm{Na}$ leitura da corporeidade e da sexualidade, o discernimento ocorre a partir do ethos ${ }^{3}$ e da visão de mundo, que já foi sistematizado e acumulado na identidade de gênero.

Nossa linguagem sobre Deus é sexuada, não trans-sexual (...). Por isso, o trágico está no predomínio absoluto, exagerado, do Deus masculino. Palavras femininas neste ou naquele idioma, para falar de deus, de modo algum o tornam feminino. Pensa-se em Javé como sujeito sempre masculino (Croatto, 2001, p. 20).

\footnotetext{
O ethos de um povo é o tom, o caráter e a qualidade de sua vida, seu estilo moral e estético, e sua disposição é a atitude subjacente em relação a ele mesmo e ao seu mundo que a vida reflete. A visão de mundo que esse povo tem é o quadro que elabora das coisas como elas são na simples realidade, seu conceito da natureza, de si mesmo, da sociedade (Geertz, 1989, p. 92).
}

De fato, a constituição da identidade de gênero é uma construção de representações sociais que se legitima a partir de concepções estabelecidas socialmente. As pessoas pensam e agem por meio de modelos construídos ao longo do tempo. Diz-nos Croatto (2001, p. 21) que falar do feminino a partir de modelos e paradigmas pré-estabelecidos culturalmente, reforça ainda mais a legitimação da divindade masculina e patriarcal.

\section{Considerações finais}

Em nossa cultura religiosa do Centro-Oeste, se faz bem presente a idéia da preferência de Deus pelo masculino. É muito comum a leitura tradicional do texto bíblico de Gênesis, 3, quando se trata da criação. Segundo essa leitura, a mulher precisou de parte do homem para existir. Por outro lado, a mesma não foi confiável. Ela levou o homem ao caminho do mal. A construção histórica literária do paraíso relacionou a mulher à serpente. Todos os atributos negativos da serpente foram-lhe atribuídos. Ou seja, a mesma "maldição" que foi atribuída à serpente também atingiu a mulher. Essa mesma idéia pode ser visualizada em diferentes espaços culturais, como o que ocorreu no filme de Mel Gibson, Paixão de Cristo, que reproduziu a cena do diabo. Na referida cena, viu-se nada mais nada menos que uma mulher como figurante. No entanto a mesma concepção foi percebida ao assistir as encenações da Sexta-Feira da Paixão, na encenação da Paróquia Divino Espírito Santo, em Goiânia, em 2003. Na maior parte da encenação, se imitava o filme. A reprodução da cena foi quase fiel ao filme e, novamente, viram-se mulheres figurando o diabo, sendo que a maioria dos figurantes na cena eram homens.

Portanto, por representação, a masculinidade se sente co-participante da criação. Os atributos da divindade, como a honra, a honestidade, a justeza, a responsabilidade, são percebidos também nos dados obtidos na pesquisa de campo como valores inerentes e necessários para a ordem social. Para evidenciar isso, concluímos com a afirmação da pesquisa que diz: "ser homem é uma coisa dada de Deus, eu sinto muito honrado por ser homem, eu trago isso do berço, eu acho ótimo ser homem e acho uma palavra bonita". É possível afirmar, a partir da análise dos entrevistados da Região Leste de Goiânia, que há uma forte tendência do homem nas relações sociais, ser pensado a partir da herança Bíblica cultural de Deus Pai todo poderoso. A imagem de toda a masculinidade reside nos arquétipos de um Deus que é homem e todo Poderoso, de quem deriva toda a paternidade, tanto no céu como na terra. A família e a paternidade reforçam a hierarquia social da masculinidade. 


\section{Referências Bibliográficas}

Bourdieu, P. (1998). A economia das trocas simbólicas. São Paulo: Perspectiva.

Bourdieu, P. (2005). A dominação masculina. Rio de Janeiro: Bertrand Brasil.

Cecchetto, F. R. (2004). Violência e estilos de masculinidade. Rio de Janeiro: FGV.

Croatto, J. S. (2001). A sexualidade da divindade: reflexões sobre a linguagem acerca de Deus. Revista de Interpretação Bíblica Latino-americana, Petrópolis: 38, 16-31.

Dalarun, J. Olhares de clérigos. In: G. Duby \& M. Perrot (1990). História das mulheres: a idade média. Porto: Afrontamento/ São Paulo: Ebradil.

Fuller, N. (2001). Masculinidades. câmbios y permanências. Pontifícia Universidad Católica Del Peru: Fondo Editoria.

Geertz, C. (1998). O saber local: novos ensaios em antropologia interpretativa. Petrópolis: Vozes.

Geertz, C. (1989). A interpretação das culturas. Rio de Janeiro: Zahar.

Paden, W. E. (2001). Interpretando o sagrado: modos de conceber a religião. São Paulo: Paulinas.

Schwantes, M. (2001). Projetos em conflito (Gênesis 2-3). In: M. Schwantes, Projetos de esperança. meditações sobre Gênesis 1-11 [p.103-121]. São Paulo: Paulinas.

Clóvis Ecco - Graduado em Filosofia e Teologia, tem Especialização em Psicopedagogia e Ensino Religioso e é Mestre em Ciências da Religião pela Universidade Católica de Goiás. Atua como Professor e é autor do livro Um retrato de homem contemporâneo (Editora Descubra). E-mail: <clovisecco@uol.com.br>

Recebido em 23.05.08

Primeira Decisão Editorial em 06.08.08

Aceito em 16.09.08 